\title{
El día a día de la guerra contra Chile. Cotidianidad y ciudadanos (1879-1882)
}

\section{Day to day of war against Chile. Everydayness and citizens (1879-1882)}

\section{Emilio Rosario ${ }^{1}$}

Universidad Privada del Norte. Lima, Perú emiliorosario981@gmail.com

Citar como: Rosario, E. (2018). El día a día de la guerra contra Chile. Cotidianidad y ciudadanos (1879-1882). Desde el Sur, vol. 10, nro. 2, pp. 469-492.

\section{RESUMEN}

En este trabajo desarrollaremos la vida cotidiana durante la guerra contra Chile desde los inicios de 1882. Nos enfocaremos en el comportamiento de la población durante los principales acontecimientos del conflicto, como las pérdidas en batallas y combates, la huida del presidente Mariano Ignacio Prado y la llegada de los chilenos a la capital. Para ello, utilizaremos los relatos de diversos autores, como Ricardo Palma, Dora Mayer, entre otros testigos de la época, quienes nos apoyarán en la realización de nuestro discurso.

\section{PALABRAS CLAVE}

Perú, Lima, Guerra del Pacífico, testimonios, intelectuales

\section{ABSTRACT}

In this article we will present the development of daily life during the war against Chile, since the beginning of 1882 , focusing on the behavior of the population during the main events such as losses in battles, the flight of President Mariano Ignacio Prado and the arrival of Chilean troops to Lima. We will quote the testimony of authors such as Ricardo Palma and Dora Mayer, among other witnesses, to support our arguments.

1 Historiador con Maestría en Literatura y docente universitario. Candidato a doctor en Historia con una tesis sobre Abraham Valdelomar. Actualmente realiza un estudio sobre los aportes culturales de Luis Alberto Sánchez. 


\section{KEYWORDS}

Peru, Lima, War of the Pacific, testimonies, intellectuals

\section{Introducción}

La situación política en la capital peruana a inicios de enero de 1881 era de caos político y temor absoluto en la población, debido al ingreso de las tropas chilenas a la capital. Fueron muchos los peruanos testigos de las acciones cometidas por el Ejército de Chile durante esta etapa y a lo largo de la guerra; pero es limitado el número de ciudadanos que se atrevieron a escribir el día a día de tan trágicos acontecimientos, por temor a represalias en su contra. Sumemos a ello la escasez de fuentes escritas por la falta de una tradición académica en nuestro país que promoviera la reproducción de los libros-memoria y contemplara la evidencia escrita sobre la vida republicana durante esta época. Al abordar los llamados autodocumentos, según Mücker y Velásquez, debemos considerar diversos aspectos para una evaluación objetiva:

Estudiar autodocumentos implica estudiar las prácticas de escritura tanto a nivel social como a nivel personal. Hay que saber quiénes escribían y cómo lo hacían; hay que tratar de averiguar en qué contexto y de qué manera se produjo el texto. Sin saber esto, es imposible conocer en qué códigos sociales y culturales se movía el autor. Y tampoco se sabrá cuál era su rango de desplazamientos y su horizonte de opciones entre diferentes modelos narrativos, ni si podía desarrollar sus propios modelos discursivos, etc. Si solo estudiamos los escritos autobiográficos de escritores reconocidos, no nos vamos a dar cuenta de los diversos circuitos culturales de la escritura dentro de una sociedad (Mücke y Velásquez, 2015, p. 28).

Nosotros los hemos llamado los libros-memoria, debido a sus características físicas y constitución interna. Para nuestros intereses nos enfocaremos en aquellos relacionados con la guerra contra Chile, cuyo objetivo central era atestiguar sobre el desarrollo político y bélico de este importante acontecimiento. Existen distintas formas de explorar académicamente dichas fuentes, sin seguir estrictamente la intención original de su autor. El trabajar la vida cotidiana del pasado resulta un reto mayor, porque debemos intentar reconstruir de forma pormenorizada una realidad ajena a la nuestra con sus propias características y costumbres. Durante el proceso de exhumación documental concatenaremos los párrafos en donde clandestinamente se encuentra la información requerida y, para su afianzamiento, realizaremos un diálogo intertextual entre los libros-memoria, lo que nos permitirá una relación más cercana a dicha realidad. De esta manera, entenderemos, por ejemplo, las siempre 
complejas relaciones de género, las costumbres sociales, las tradiciones cívicas, la vestimenta, la dieta alimenticia, entre otros aspectos, tal como señala Michel de Certeau (1996, p. 81):

Este conocimiento no se conoce. Ocupa, en las prácticas, una situación análoga a la que se otorga a las fábulas o a los mitos de ser las expresiones de conocimientos que no se conocen por sí mismos. De una y otra parte, se trata de un conocimiento que los sujetos no reflexionan. La presencian sin poder apropiárselo. Sin finalmente inquilinos y no los propietarios de su propia habilidad práctica. En cuanto a sus intenciones, uno se pregunta si hay conocimiento (se supone que debe hacerlo), pero es conocido solamente por otros que no son sus portadores. Como el de los poetas o los pintores, la habilidad de las prácticas diarias solo sería conocida por el intérprete que lo ilumina en su espejo discursivo, pero tampoco lo posee. Así, no es de nadie. Circula de la inconsciencia de los practicantes a la reflexión de los no practicantes, sin depender de ningún sujeto. Es un conocimiento anónimo y referencial, una condición de posibilidad de prácticas técnicas o doctas.

En este trabajo revisaremos la vida cotidiana durante la guerra contra Chile desde inicios de 1882. Nos enfocaremos en el comportamiento de la población durante los principales acontecimientos del conflicto, como las pérdidas en batallas y combates, la huida del presidente Mariano Ignacio Prado y la llegada de los chilenos a la capital. Para ello, utilizaremos los relatos de diversos autores, como Ricardo Palma, Dora Mayer, entre otros testigos de la época que nos apoyarán en la realización de nuestro discurso.

\section{Los inicios de la guerra}

De enero a febrero de 1879, los principales diarios capitalinos, como El Comercio, La Opinión Nacional y El Peruano, informaban a través de sus líneas editoriales y notas periodísticas la accidentada llegada del plenipotenciario peruano José Antonio Lavalle a Chile. La presencia del embajador nacional tenía como objetivo intermediar en las tensas relaciones entre Bolivia y Chile, que fueron alteradas dramáticamente por la invasión militar a la provincia boliviana de Antofagasta. El pretexto principal de la invasión era el incremento del impuesto al barril de salitre por parte del Gobierno altiplánico, lo que violentaba el acuerdo inicial con los chilenos, que obtuvieron la comercialización del barril salitrero a un precio ínfimo durante el Gobierno del presidente boliviano Mariano Melgarejo. La recepción por parte de la muchedumbre valparisina hacia nuestro compatriota no fue hospitalaria. Por el contrario, la agresión y el acoso sufrido fueron permanentes: "Desde el muelle hasta el hotel de su alojamiento fueron con el cónsul general del Perú, entre dos filas de 
policías y estrechados a cada paso por una muchedumbre airada y enemiga, como reos que llevan el suplicio» (Paz Soldán, 1979, p. 61).

Mariano Felipe Paz Soldán, ministro de Gobierno durante el primer año de guerra, testigo preferencial, describe detalladamente la tensa situación que se vivía las semanas previas a la declaratoria de guerra (5 de abril de 1879). Él nos señala que la prensa nacional durante los primeros meses del año se especializó en agitar los ánimos de la población al presentar en sus titulares y notas informativas la agresiva actitud chilena en contra de los intereses nacionales, lo que provocó distintas manifestaciones públicas en contra de Chile:

la prensa y el pueblo, que deseaban la guerra, celebraban meetings tumultuosos; se repartían impresos rechazando la medición; relacionando con torcida y malévola interpretación, cuando hacía o no hacía, y cuanto suponían pensaban hacer la legación peruana, y aconsejando que se le contestara que el Gobierno de Chile, después de agotados todos los medios de conciliación, estaba en el primer propósito de mantener la definitiva reivindicación del litoral boliviano. Esto se decía antes de haber llegado al ministro mediador y se repetía cuando aún no existía ninguna comunicación escrita, ni tenido ninguna entrevista con el ministro de Relaciones Exteriores o con el presidente de la República (Paz Soldán, 1979, p. 62).

El fracaso de la misión Lavalle y la sospecha de una preparación militar inminente del Perú generaron la inmediata declaratoria de guerra por parte de los chilenos (5 de abril de 1879). Tal acción radicalizó aún más los ánimos de la población nacional, que recibió con entusiasmo y mucha euforia el afrontar un conflicto internacional, que en apariencia tenía que ser favorable a nuestro país. Los indicadores de la excesiva confianza radicaban en la figura del rival, geográficamente mucho más pequeño e históricamente irrelevante (por su falta de tradición histórica); más aún, Chile se enfrentaría a dos países que en cantidad poblacional los superaban ampliamente, y uno de ellos -el Perú - de alta trascendencia en el continente americano, porque fue la capital del imperio colonial hispánico.

De esta manera, las diversas calles de Lima se convirtieron en lugares donde la emoción y la algarabía entre plebe y élite se mezclaban, olvidando por un momento las diferencias sociales que los dividían para enfrentar al enemigo común, que amenazaba el bienestar de la nación.

Los chilenos residentes en la capital peruana serían testigos de las manifestaciones públicas en contra de su país:

El pueblo de Lima, al saber la noticia, recorría las calles y llenaba las plazas dando vivas al Perú y aceptando con alegría la guerra; fue aquel un día de verdadero júbilo y ardoroso entusiasmo. En medio de 
esa multitud exaltada se paseaban, sin embargo, tranquilos y respetados, muchos chilenos notables avecindados en Lima (Paz Soldán, 1979, tomo I, p. 109).

A comparación de los desmanes propiciados en detrimento de las propiedades nacionales y acoso sufrido por nuestros compatriotas en Chile, en nuestro país se respetó la investidura de los plenipotenciarios y las propiedades e incluso el bienestar físico de los ciudadanos rivales. Con ello, Paz Soldán quería demostrar que nuestra patria era una nación ordenada y responsable que enfrentaba a la barbarie chilena:

el ministro de Chile Joaquín Godoy, que vivía a pocos metros de distancia de la casa de los ministros de Bolivia, fue respetado, a pesar de que la casa de estos se hallaba invadida por inmensos y continuos grupos de pueblo que los felicitaba. El escudo de Chile se ostentaba en la puerta de la legación hasta el día 4, sin que nadie intentara siquiera ultrajarla (Paz Soldán, 1979, tomo I, p. 109).

Pero este acto de «caballerosidad» no era impedimento para que los peruanos expresaran su repudio público en contra de Chile y ofrecieran vivas a nuestro país durante el primer mes de guerra. La excitación nacionalista recorrió todos los rincones de la capital; por las mañanas se apreciaba a cientos de jóvenes enlistarse voluntariamente en el ejército, y en las tardes las damas de alta sociedad se encargaban de recolectar dinero para afrontar la guerra mediante actividades públicas como bailes y degustación de viandas. En líneas generales, se percibía un ambiente de triunfo a priori por parte de la masa poblacional peruana. La excesiva confianza en el ambiente nacional era producto del bombardeo periodístico emitido diariamente, que maniataba las mentes del pueblo al construir en notas editoriales un escenario en donde el Perú y Bolivia eran superiores en todo aspecto a su rival, por los motivos descritos en párrafos anteriores:

los meetings o reuniones populares continuaron varios días con igual orden y entusiasmo; multitud de personas se presentaron a engrosar las filas del ejército; pobres y ricos concurrieron a depositar sus erogaciones en las arcas nacionales; la suma de estos donativos ascendía a centenares de miles, desde los primeros días; y los ofrecidos periódicamente aseguraban al fisco una entrada de más de 200000 soles mensuales, por algún tiempo (Paz Soldán, 1979, tomo I, p. 109).

La parte religiosa también estuvo inmiscuida en este proceso, dado que debía garantizar la bendición divina en favor de las tropas nacionales $y$, de esta manera, con el respaldo de Dios, garantizar el triunfo de las armas nacionales: 
El clero peruano fue ajeno al concepto de la guerra justa. La visión agustiniana del conflicto internacional fue un elemento clave en la pastoral que el arzobispo limeño Francisco Orueta envió a sus fieles el 5 de abril de 1879, con motivo del inicio de las hostilidades. Publicaba, en ese mismo año, la carta de Orueta que subrayó que cuando Perú ofrecía su generosa mediación para evitar la lucha entre dos repúblicas hermanas, Chile reaccionó declarándole la guerra. Orueta opinaba que no se podían romper de una manera radical los antiguos vínculos de dos pueblos con tradiciones e historias compartidas. Ante tan evidente injusticia por parte de Chile, Orueta apelaba al vínculo entre patria y religión, convocando a los peruanos a pelear con la convicción que Dios estaba de su lado (Mc Evoy, 2011, p. 180).

Como apreciamos en las primeras páginas del texto Narración histórica de la guerra de Chile entre el Perú y Bolivia (compuesto por tres tomos), el objetivo central era presentar una nación unida que enfrentaría y derrotaría categóricamente a Chile; pero dicho discurso tenía como objetivo defender el rol jugado por Paz Soldán como parte del Consejo de Ministros durante los inicios de la guerra. Sin embargo, él no fue la única persona que describirá esta etapa. El italiano Tomás Caivano señalaba que las condiciones sociales de nuestro país para afrontar un conflicto bélico de escala internacional eran sumamente difíciles, debido a la desunión histórica entre los peruanos, que nunca habían logrado una victoria frente a un rival exógeno desde su nacimiento como República. Por el contrario, su prioridad era destruir a otro peruano que podía atentar contra sus intereses personales o de grupo. Los odios endógenos provocaron incluso la desarticulación de las fuerzas armadas, para evitar algún golpe de Estado:

no era ciertamente mejor su situación política. Dividido por las discordias intestinas; punto de mira de las riendas del Gobierno, de la ambición más o menos desenfrenada de inquietos partidos que, ora vencedores, ora vendidos, no dejaban desde largos años de hacerse la guerra, las veces sorda y latente, otras amenazadora y violenta, el Perú había llegado a un estado en el cual, puede decirse sin exageración alguna, que faltaba moralmente de unidad política. Y bien que hubo la amenaza de una revolución, el Gobierno se había visto obligado a desarmar su escuadra y a reducir casi completamente su ejército, por dos razones, en primer lugar por falta de medios, y luego para impedir que la revuelta se llevase a efecto con sublevaciones de cuartel y de las tripulaciones navales, con pronunciamientos como casi siempre comenzaron todas las revoluciones peruanas (Caivano, 1969, p. 69).

En este dialéctico escenario descrito durante el primer mes de conflicto bélico, Mariano Ignacio Prado asumió el mando de las Fuerzas Armadas 
nacionales, en su calidad de presidente de la República. Su primera tarea fue trasladarse hacia la ciudad portuaria de Arica a comandar personalmente a las Fuerzas Armadas peruanas y coordinar con los bolivianos acciones conjuntas en contra del rival.

Uno de los trabajos iniciales desarrollados por el Gobierno nacional fue apertrechar rápidamente a las primeras tropas destacadas en el teatro de operaciones sureño. Para ello, debían ser movilizados los recursos necesarios, tanto en armas, vestidos, medicinas y alimentos, que permitirían a los soldados desenvolverse de manera efectiva. La burocracia estatal ingresó a negociar directamente con los ganaderos sureños para proveer de carne a las tropas. Las poblaciones de Puno, Arequipa y Tacna fueron testigos del desplazamiento de cientos de cabezas de ganado hacia el puerto de lquique, con el fin de cubrir la ingente demanda alimenticia que significaba alterar la demografía de las ciudades fronterizas, como Arica y Tarapacá, al ingresar miles de hombres y mujeres relacionados directa o indirectamente con las Fuerzas Armadas. Asimismo, se debía abastecer de agua potable a los batallones peruanos, lo que era toda una odisea, más aún en ciudades desérticas donde este producto escaseaba. El cuidado y la convocatoria de profesionales fueron necesarios para racionalizar los recursos y mantener en funcionamiento las máquinas locales para el óptimo desenvolvimiento de las tropas nacionales:

Aprovechando de la cañería de fierro establecida por una compañía salitrera, para conducir el agua salitrosa hasta lquique y condensarla allí, la puso en contacto con el manantial de agua inmediata; de este modo lquique no podía perecer de sed. Los chilenos que de pronto ignoraban el gran abastecimiento de lquique y la facilidad con que el Ejército peruano-boliviano se proveía de agua, creyeron muy fácil rendir a la población por hambre y sed; por esto se empeñaba su escuadra en destruir las máquinas condensadoras y en impedir la entrada de víveres por los puertos inmediatos; tarde conocieron su error y qué más provecho habrían reportado empleando sus naves en otro género de hostilidades (Paz Soldán, 1979, tomo II, p. 29).

La vida en Lima en junio y julio generó una mayor actividad. Mientras caminaba por las calles, Caivano nos relata la llegada de cientos de soldados de distintas partes del país, sorprendidos por la estructura arquitectónica de la capital. Los soldados le causaron admiración porque eran capaces de soportar condiciones adversas como el frío o el hambre, y combatir hasta ofrendar su vida. Pero Caivano señala que este comportamiento no respondía a una sólida formación cívica impartida por el Gobierno central desde el nacimiento de la República y transferida de manera efectiva a la población; esa actitud era producto de un comportamiento 
sumiso, amoldado durante muchos siglos, con el habitante de los Andes sometido física y espiritualmente a la «voluntad» del hombre «blanco»:

el soldado peruano tiene pocas pretensiones: eminentemente sobrio en tiempos ordinarios, soporta fácilmente toda clase de privaciones en casos excepcionales, sin lamentarse o por lo menos sin mucha insistencia; y es capaz, en casos dados, por simple pasividad de obediencia y hábito de sufrir, principalmente el de las provincias del interior, o sea el cholo, el indio, de hacer las marchas más duras y fatigosas. Es obediente a la disciplina y fiel a la consigna; y si bien falte de arrojo e iniciativa, se bate, sino por verdadero y propio valor, con la imperturbable serenidad y constancia que le dan su natural disposición a la más pasiva obediencia, y su suma indiferencia a la faz del peligro (Caivano, 1969, p. 252).

La descripción sobre la composición social de las tropas nacionales fue descrita por Adriana Verneuil de González Prada. Ella señalaba que la lengua predominante entre los soldados era el quechua, muchos de ellos iban mal vestidos y habitaban en lugares de condiciones sanitarias calamitosas (Verneuil de González Prada, 1947). La descripción física de forma meticulosa fue realizada por el inglés Clements Markham: «La estatura media del indígena peruano es de cinco pies a cinco y ocho pulgadas. Es corto, pero de reacia estructura muscular y capaz de soportar grandes fatigas. Sus rasgos especiales son: color de aceituna fresca, piel lisa y suave, pelo lacio y negro» (Markham, s.f., p. 54). Es importante mencionar que Markham fue muy criticado debido a que su texto colocaba al peruano en víctima y al chileno en victimario, leyenda que aún tiene una fuerte vigencia en la historiografía nacional.

Un personaje poco mencionado en los textos históricos es la rabona, de gran sacrificio durante esta coyuntura, que acompañó al soldado peruano en los combates en las provincias sureñas (Arica, Tacna y Tarapacá). Los extranjeros las observaban con mucha extrañeza, porque en su concepción no era un lugar propio para las mujeres. En su mentalidad las damas debían esperar a esposos, hermanos, padres e hijos en casa, para celebrar con ellos la victoria o cuidarlos en caso de la derrota. Ellas eran catalogadas como la fiel compañera, brazo de apoyo importante en este proceso bélico:

se le permite a las mujeres de los reclutas, llamadas rabonas, seguir a los regimientos en que sirven sus maridos. No reciben ración sino que se alimentan con parte de la que toca a sus cónyuges. Estas fieles y sufridas criaturas siguen a los ejércitos en sus largas y fatigosas marchas, llevando las mochilas y los utensilios de cocina, carga que a veces se agrava el peso de un niño de pecho. No bien se hace alto, 
la rabona se afana en preparar el alimento de su marido (Markham, s.f., p. 54).

Conforme pasaron los meses, la animosidad y algarabía de la población limeña fueron mermándose, por los reajustes económicos que alteraron la vida del país. Las secuelas fueron el despedir a cientos de trabajadores estatales, el encarecimiento de los productos de primera necesidad e incluso la disminución de la capacidad adquisitiva de la población. Los resultados bélicos tampoco fueron favorables a los intereses de nuestro país. El evento que causó conmoción en la población limeña durante el primer año de confrontación militar fue la pérdida de Angamos (octubre de 1879), que provocó incertidumbre frente a un futuro casi incierto. El perder las fuerzas navales ocasionaba la casi derrota absoluta en la guerra, ya que las tropas no podían ser transportadas inmediatamente a las zonas de conflicto. Además, era muy difícil el traslado efectivo de los pertrechos para afrontar la guerra.

La derrota de Angamos significó un fuerte golpe para los intereses nacionales. En Chile la celebración de la población fue ingente, porque también eran conscientes de un gran avance en su empoderamiento bélico:

La captura del Huáscar despertó en Chile un entusiasmo indescriptible. Luego del combate de Angamos (8 de octubre), una curiosidad inmensa y febril por ver al monitor peruano con bandera chilena se apoderó de todo el país. En su viaje de incorporación a las Fuerzas Armadas del antiguo enemigo, el buque altar donde se había inmolado Prat fue fondeando en Chañaral, Caldera, Huasco y Coquimbo. En cada uno de estos puertos, los habitantes acudieron en romería para verlo. Fue tanta la excitación que provocó la captura del legendario monitor entre la población chilena que en Valparaíso fue necesario organizar trenes especiales para trasladar desde el interior a las personas de toda condición y sexo que deseaban verlo (Mc Evoy, 2011, p. 151).

La pérdida de nuestra Marina de Guerra provocó el retorno inmediato de Mariano Ignacio Prado a la capital. La población lo recibió el 28 de noviembre con respeto y consideración, en la estación Desamparados, desde donde emprendieron una marcha a pie hasta su domicilio. En esta caminata lo acompañaron personas de toda composición social, expectante por las respuestas del primer mandatario en torno a la posición del Perú en la guerra y cómo afrontarla tras la derrota naval. Sin embargo, en este encuentro entre el presidente y su pueblo no encontraron solución alguna: «Reinó un profundo silencio; porque aun cuando se conocían sus errores en la dirección de la guerra, nadie dudaba de su ardiente patriotismo» (Paz Soldán, 1979, tomo II, p. 68). 
Pocos días después del retorno de Prado a Lima, este abandonó el país con el pretexto de comprar armamento en el extranjero. Si bien intentó salir de forma clandestina, el rumor se expandió rápidamente y no tuvo éxito. Cientos de conciudadanos lo esperaron en el puerto del Callao para despedir al líder. Frente a este escenario, Prado fue obligado a emitir un discurso público en el que narró las principales causas de su repentina partida. Señaló que tomaba esa decisión en contra de su voluntad, porque era difícil abandonar el país en una situación que exigía su presencia, pero esta acción tenía que ser respetada por la población ya que «el hombre que como yo sirve al país con buena voluntad y completa abnegación» (Caivano, 1969, p. 309) nunca dejará los designios a los que fue encomendado.

La respuesta por parte de la ciudadanía no fue comprensiva. Por el contrario, quedó estupefacta frente a tal actitud y provocó en lo inmediato rumores a diestra y siniestra sobre la partida repentina del presidente. El más importante fue el millonario saqueo hecho a la caja fiscal y el robo a las donaciones realizado por un sector de la población capitalina. El trabajo periodístico del diario oficial El Peruano para calmar los excitados ánimos de una población cada vez desilusionada con su clase política no fue suficiente para mermar los comentarios desfavorables vertidos por la prensa opositora, encabezada por El Comercio, que tuvo una alta recepción en la recelosa ciudadanía limeña. Esta situación de cuasi anarquía generó una oportunidad en «los sediciosos de profesión» (Caivano, 1969, p. 310) para tomar las riendas del país. El ambiente de victoria y confianza de los primeros meses se desmoronaba velozmente frente al escenario de derrota, crisis económica e inquietud emocional.

El nuevo régimen encabezado por Luis La Puerta, vicepresidente de la República encargado de los destinos del país, no tuvo la capacidad de mermar la desconfianza de la población tras el retorno de los primeros caídos en combate, que generaba múltiples ceremonias fúnebres en la capital. A pesar de estas noticias que acrecentaban la desconfianza en la dirigencia política, debemos resaltar que la población fue un tanto injusta con los esfuerzos desarrollados por la administración estatal para sostener la empresa bélica, más aún cuando no contaban con los recursos económicos y el respaldo material en suficiente:

El Gobierno del vicepresidente La Puerta había llegado a su completo desprestigio. En los últimos meses, desde octubre, el ejército del sur no había sido atendido sino con pequeños auxilios, que en nada aumentaban su fuerza, ni mejoraban su armamento. Los numerosos pedidos de rifles y municiones, y la aglomeración de fondos de Europa para la compra de blindados, se hicieron tan en secreto, que el 
pueblo, ignorándolo en lo absoluto, no tomaba esto en cuenta para sus juicios sobre la administración (Paz Soldán, 1979, tomo Il, p. 88).

Esta situación generó una ingente debilidad en el régimen central, lo que provocó su fácil cuestionamiento por parte de Piérola, quien organizó un exitoso golpe de Estado que aceleró la descomposición política del país.

\section{0}

El 2 de noviembre de 1879, el burgomaestre capitalino general Manuel González de la Cotera emitió un comunicado a la opinión pública para expresar su profundo malestar frente a los lamentables incidentes ocurridos unos días atrás en las instalaciones de Palacio de Gobierno ${ }^{2}$. Según informaba, la también conocida Casa de Pizarro fue tomada por cientos de hombres armados con rifles y palos con una sola consigna: derrocar al régimen encabezado por el primer vicepresidente Luis La Puerta (Rosario, 2013).

Cumplido el objetivo de la enardecida masa, realizaría su aparición un nuevo actor pero viejo protagonista de la política nacional: Nicolás de Piérola Villena, líder del grupo, que se dirigió a ellos a través de un emotivo discurso. Entre las frases más efusivas estuvieron aquellas que resaltaron la incapacidad, mediocridad e irresponsabilidad de los hombres de negocios y los politiqueros de antaño que llevaron al país hacia la derrota (Fuentes, 1881).

El ingreso de Piérola al poder ocurrió gracias a la desilusión de la población, que proyectaba en él a la única figura en capacidad de invertir la situación bélica del país. Además, no existía una real posición con respaldo popular que frenara sus objetivos. Recordemos que gran parte de la oficialidad había sido destacada a la frontera sur y los líderes políticos nacionales no tenían la capacidad de enfrentarse al pierolismo. Caivano señala que las milicias pierolistas que ayudaron a concretar el golpe de Estado estaban constituidas por habitantes de la zona andina. Por tanto, deducimos que su apoyo mayoritario provino de los terratenientes serranos.

Las primeras acciones del régimen pierolista fue reconfigurar la oficialidad del ejército, colocando en puestos estratégicos a personas leales a su Gobierno, sin importarle su capacidad o experiencia en el campo de batalla, lo que aceleraría nuestras derrotas militares:

y si a todo esto se añade que, excepto pocos oficiales buenos y expertos de los ya existentes, los demás eran todos oficiales de creación

2 Manifiesto del general González de la Cotera (Biblioteca Nacional del Perú, Sala de Investigadores, x.985.06/m). 
reciente, que poco o nada conocían del arte militar, se comprenderá fácilmente con cuánta razón decíamos antes que el ejército levantado y dispuesto por Piérola, más bien que tal, podía apenas llamarse una simple aglomeración de gente armada (Caivano, 1969, p. 384).

Asimismo, la cada vez más difícil manutención de las tropas para proveerles insumos bélicos provocaría la derrota del Alto Alianza y Arica; en esta última batalla sería liquidado el ejército «profesional» y se dejó el país a merced del enemigo. A pesar de las conversaciones en la embarcación norteamericana Lackawanna para finiquitar la guerra, esta no llegó a buen puerto por las elevadas exigencias de Chile de anexarse gran parte de la zona sur del Perú.

Los efectos de la guerra comenzaron arreciar en la vida cotidiana de los hogares peruanos, al punto que los productos de primera necesidad aumentaron astronómicamente de precio:

Libra de arroz del país, 0,20 soles; de la India, 0,19 soles; azúcar blanca, 0,35 soles; mascabada, 0,25 soles; carne fresca de vaca de primera clase, 0,50 soles; de segunda, 0,40 soles; de tercera, 0,30 soles; de chancho, 0,60 soles; de carnero de primera, 0,60 soles; de segunda, 0,50 soles; camote, 0,05 soles; carbón vegetal, 0,05 soles; frejol blanco, 0,13 soles; prieto, 0,13 soles; galleta, 0,40 soles; garbanzos, 0,20 soles; harina de trigo, 0,25 soles; de maíz, 0,15 soles; lentejas, 0,18 soles; manteca extranjera, 0,70 soles; del país, 0,60 soles; papas, 0,07 soles; pallares, 0,20 soles; pan de 140 a 180 gramos, 0,10 soles; sal, 0,05 soles (Zanutelli, 1981, p. 25).

Estos precios eran considerados sumamente elevados para las clases populares, lo que incrementaba la angustia y carencia de dinero para la compra de lo más elemental para sobrevivir.

Las victorias chilenas en el campo de batalla sureño no eran suficiente para lograr su objetivo principal: la apropiación definitiva de la provincia salitrera de Tarapacá. Chile procedería al bloqueo marítimo sobre el puerto del Callao, el más importante del país, para desabastecer de productos de primera necesidad a la capital. De esta manera, se podría acelerar el proceso de inestabilidad en la población, lo que provocaría caos y, por ende, presión al Gobierno para ceder a las condiciones chilenas. La carencia de alimentos en los mercados es testimoniada por Dora Mayer; incluso las élites tuvieron que cambiar radicalmente su dieta alimenticia derivándola a pescado, un producto casi exclusivo en los paladares populares. El bloqueo marítimo también generó la escasez de pan, tan importante en la dieta alimenticia peruana, y generó serias confrontaciones físicas en la población por intentar conseguirlo en las distintas plazas limeñas, donde era distribuido: 
previendo las perturbaciones comerciales mi papá compró un quintal de arroz y un quintal de frijoles cocachos; una arroba de azúcar, dos panes de azúcar, y un cajón de té chino. Mi mamá, que apuntaba los gastos diarios, anotó precios del pan y otros artículos de primera necesidad, muy parecidos a los que rigen en la presente posguerra. Sin duda no había carne, pues en esa época llegué a conocer todas las clases de pescado de nuestras aguas marinas que quedaban entonces para alimento barato del pueblo, como no sucede ahora. Casi todos los días se comía ayanque, cojinova y con gran preferencia jurel, una especie que desde hace tiempo no he visto más en el mercado local. Contra bonito y lorna tenían prejuicio mis padres, y en cambio no aspiraban ellos a los pescados de primera clase, la corvina, el robalo, el pampero, la lisa, o solo a veces el lenguado y al pejerrey. Una vecina y amiga nuestra nos hizo aquellos días un regalo extraordinario consistente en un buen atado de cebollas. No se hacia cola para el pan, sino que se luchaba por ese artículo a codazo limpio ante los kioscos municipales que se había instalado en la plaza de abastos. Debe de haber escaseado completamente el pan a consecuencia del bloqueo en 1880, pues recuerdo que mi mamá cocinaba camotes para el desayuno, mientras yo me entretenía con un libro ilustrado, acompañándola en el corral (Mayer, tomo II, 1981, p. 126).

Pero esta presión duró poco tiempo. La Marina chilena no tuvo la capacidad para prolongar el bloqueo, lo que produjo un clima de malestar al interior de Chile por una guerra que se alargaba demasiado y provocaba terribles estragos a su economía. Ello conllevó a la decisión de invadir Lima y obligar a la rendición del Estado peruano. Frente a tal amenaza, Piérola convocó a las tropas reservistas para la defensa de la capital, pero su personalismo obnubiló el consejo de los oficiales de experiencia para realizar una labor decorosa. Además, recordemos que los batallones nacionales estaban conformados por soldados sin experiencia alguna y apertrechados con armas de fabricación variopinta:

Esto provenía en gran parte de que Piérola, deseando aparecer como el único y exclusivo director de la guerra, hasta en sus más pequeños detalles, comunicaba sus órdenes, y se entendía directamente con los jefes de oficinas subalternas, o con los comandantes generales, sin previo aviso al estado mayor general, sembrando así el desorden y la confusión, y perdiendo la unidad y la disciplina militar; tan grave mal llegó al extremo de que se desobedeciera más de una vez las órdenes del jefe de estado mayor general; porque las recibidas por los jefes de división o de batallón, dadas por el jefe supremo, eran contrarias. ¿Podía conseguirse así el triunfo? (Paz Soldán, 1979, tomo III, p. 26). 
Esta situación provocó que la capital enfrentara una guerra que su élite económica había provocado, pero cuyas secuelas jamás habían planificado.

\section{1}

Finalizada la batalla del Alto de la Alianza (Tacna, 1880), con la victoria de Chile, el general ayacuchano Andrés Avelino Cáceres trasladó a los heridos hacia la capital y abandonó casi a su suerte a las últimas guarniciones del Ejército nacional acantonadas en Arica, cuyo destino sería su derrota (junio de 1880). El retorno de Cáceres tenía el propósito de seguir las órdenes del dictador Nicolás de Piérola, quien buscaba defender la capital ante el inminente avance chileno.

Así, la defensa de Lima contó con la participación de todos. Se formaron diversos batallones que representaban a las provincias de nuestro país: Los Libres de Trujillo, Los Libres de Cajamarca, el batallón de Jauja, el batallón de Pomabamba, el Batallón de Puno, entre otros.

La planificación chilena para ocupar militarmente la capital peruana tuvo una estrategia bien elaborada durante casi seis meses, lo que nos muestra la superioridad no solo en armas, sino en estrategia militar:

Existían tres puntos para su posible desembarco: Ancón, Callao y Chorrillos. El comando eligió, por razones de orden estratégico, el último de los mencionados. Entre el 8 de noviembre y el 1 de diciembre de 1880 desembarcó en Pisco la primera división chilena, comandada por Villagrán. Con posterioridad lo hicieron las demás fuerzas en Chilca y Curayacu, punto este último de donde continuaron a Lurín y Pachacámac, donde establecieron sus puntos de adiestramiento y preparación (Rivera Serna, 1984, p. 1).

William Acland, agregado militar británico, describió desde el bando chileno las batallas de San Juan y Miraflores. Acland se convirtió en un testigo clave para describir el desarrollo de la guerra y los actos delincuenciales en contra de la población civil por parte de las tropas enemigas:

Tan pronto terminó la lucha, las tropas irrumpieron en las tabernas y las tiendas que vendían aguardiente, se emborracharon rápidamente y perdieron el control de sí mismos, y se dio lugar a escenas de destrucción y horror; que yo creo ha sido raramente visto en nuestros tiempos; las casas y las propiedades fueron destruidas, los hombres discutían y se disparaban entre ellos como medio de diversión, las mujeres fueron violadas, los civiles inocentes fueron asesinados. El cementerio se convirtió en un lugar en donde los soldados beodos practicaron sus orgías y hasta abrieron las tumbas para remover los cadáveres y dar paso a sus compañeros embriagados (Wu, 1986, pp. 40-41). 
El estado de agresividad y barbarie de los soldados chilenos no debe parecer extraño. Por el contrario, su conducta respondía al trato recibido por su oficialidad, de forma casi inhumana:

Estando sobrios se portaban cortésmente, siempre dispuestos a saludar a un oficial, y aunque existía mucha más informalidad entre oficiales y soldados que en nuestro servicio, eran bien disciplinados. Frecuentemente se los azotaba con una vara de posaderas, propinándoles hasta 200 azotes. En todos había crueldad, pues al luchar no daban valor a sus propias vidas, y parecían casi insensibles al dolor. Yo vi cómo dos hombres, uno con un disparo que le había atravesado las dos mejillas, y el otro, con los dedos mutilados, seguían a su grupo y continuaban peleando; he visto a otros seriamente heridos merodeando por el pueblo de Chorrillos en busca de licor, en lugar de ir al hospital; parecían tener la creencia de que estaba bien matar y aniquilar a todos sus enemigos, bien sea a sangre fría o no. Eran grandes bebedores y cuando encontraban algún licor abandonaban el campamento y escapaban completamente del control de sus oficiales, quienes no demostraron interés suficiente para detener los excesos, como debía ser (Wu, 1986, p. 52).

A pesar del heroico accionar de las líneas defensivas, estas no fueron lo suficientemente sólidas para detener el avance chileno y se produjo la ocupación militar de la capital peruana el 18 de enero de 1881. La toma de Lima se convirtió en un acontecimiento clave para la reconfiguración de toda la dirigencia nacional instaurada desde fines de 1879, tras el golpe de Estado de Piérola. Esta situación provocó la huida a la sierra central de todo el estado mayor pierolista, que dejó a la merced a la capital.

Durante la defensa de Lima es digno de resaltar el rol de la mujer, especialmente la rabona, que acompañó al soldado a lo largo de la guerra:

Durante toda la campaña, el paludismo, las fiebres intestinales y la tuberculosis produjeron más bajas que el enemigo. Así informó el doctor José Casimiro Ulloa, jefe de servicio de Sanidad. A menudo, en sus informes se quejó de las rabonas, a quienes llamaban despectivamente cantineras. El término cantinera se confunde con rabona, pero las rabonas no eran cantineras. La rabona no era una cantinera, era un hecho social diferente a la hija del regimiento que ha existido en todos los ejércitos para la diversión solaz y fugaz de los soldados. La confusión de términos es, en cierta forma, culpable de desafecto por aquella figura histórica (Parra, 1981, p. 303).

La capital peruana era un centro cosmopolita, de sus casi 100000 habitantes. El $10 \%$ lo conformaban ciudadanos extranjeros, que habían asentado sus negocios Lima, por sus condiciones para establecer una vida 
próspera y relacionarse con la clase alta nacional. La mayor parte de los ciudadanos foráneos tenía una vida de lujos:

La actividad de los negocios rivalizaba con el amor a los placeres en las orillas del Rímac. Llenaban la ciudad casas comerciales extranjeras, contratistas y negociantes, tenderos franceses e italianos, industriosos mecánicos, pero, a su lado, prosperaban también iglesias y monasterios, así como tabernas, lugares de holganza y de vicio. Ciudad vasta y atareada, palpitante con miles de ideales y deseos, con múltiples intereses, potente y complicada máquina, no fácil de destruir y arruinar sin crimen por gran parte de su destructor (Markham, s.f., p. 206).

Por aquellos días todo el lujo, las fiestas y la algarabía propias de una ciudad capital desaparecieron. Podía vislumbrarse por todos lados el luto de las familias ante la pérdida de hijos, padres, amigos e incluso algún conocido. El desconcierto en la ciudadanía se palpaba en la atmósfera emocional, no solo por la pérdida bélica, sino por la orfandad familiar. A ello debemos sumarle el exponencial aumento de alimentos por su escasez, que generaba saqueos en los puestos de venta. Se vivía un ambiente de intranquilidad en las calles y plazuelas limeñas:

Millares de ciudadanos que perecieron en las batallas de San Juan y Miraflores, en los días 13 y 15 de enero, dejaron en la orfandad a centenares de familias que no sabían quién ni cómo les darían el pan como aquellos padres, esposos o amigos les proporcionaban con su trabajo. Para aumentar sus angustias, el precio de los principales artículos de alimento, como el trigo, el arroz, la carne, etc., había subido a precios fabulosos, tanto por la depreciación del billete fiscal, cuanto por la escasez consiguiente de un largo bloqueo [...] Familias que vivían con comodidad y desahogo, con el alquiler de las casa de aquellos tres pueblos incendiados, se encontraron en tres días reducidas a la miseria, sin tener medios de subsistencia, ni casa en qué vivir ( $\mathrm{Paz}$ Soldán, 1979, tomo III, p. 111).

Mientras los balnearios ubicados al sur de Lima eran aniquilados y destruidos a cenizas, los rezagos de las tropas peruanas que fracasaron en su intento por detener el avance del Ejército chileno volverían a la capital peruana. Luis Alayza y Paz Soldán narra el ingreso de los soldados y la desazón que vivieron al no encontrar un liderazgo que los organizara para seguir luchando en favor de la integridad nacional:

Ingresamos por la plaza Dos de Mayo, seguidos por grupos de curiosos, quienes nos preguntaban si Baquedano había muerto o si lo teníamos prisionero. Nos detuvimos en la plaza de Armas, mientras nuestros jefes entraban a Palacio a pedir órdenes, pero no hallaron 
con quién entenderse; se nos mandó soltar las armas y algunos conseguimos que nos las dejasen en la ciudad si entraban los chilenos (Alayza y Paz Soldán, s.f., p. 410).

Otro personaje que resume el estado moral de las tropas derrotadas fue Pedro Dávalos y Lissón, quien participó activamente en la batalla de Miraflores y narra la tensa situación vivida a pocos días del ingreso chileno a Lima:

Acompañado de Manuel Moreira y de mi hermano Jesús entramos a Lima, a las 12 a. m. de aquel pavoroso día [...] Yo y Jesús entramos en nuestra casa. Después de efusivos abrazos, subimos al techo para enterrar los fusiles [...] Estando en la altura contemplamos las nubes rojizas que a mucha distancia iluminaban el cielo inmediato al miraflorino pueblo, aquella noche incendiado por el invasor chileno [...] Mi madre presidió la mesa donde nos sentamos a cenar. Ella, mi padre, mis chiquillas hermanas nos hacían numerosas preguntas acerca del combate [...] Más tarde llegaron mis hermanos Enrique y Florencio, y cuando confirmaron la muerte de Carlos Dávalos, ocurrida en la batalla de San Juan el 13 de enero, considerose lo ocurrido tan insignificante al compararlo con la magnitud de la desgracia nacional y con la noticia de que el día siguiente los chilenos entrarían a Lima. La saquearían y la incendiarían que nadie derramó una lágrima, ni dejó oír un lamento (Dávalos y Lissón, 1947, p. 176).

En enero de 1881 teníamos un Gobierno inexistente. El temor y la inseguridad irradiaba; esto último provino de conciudadanos armados que amenazaban la integridad de los compatriotas y un rival que ingresaría a consumar su victoria. Así también lo testimonia Zoila Cáceres en su libro La Campaña de la Breña, donde rememora un ambiente de tristeza que invadía a hombres y mujeres esperando la llegada del invasor:

Noches siniestras fueron las del 15 y 16 . Sin luz aumentaba la tristeza de sus habitantes, las moradas estaban cerradas por el común duelo de la patria, todos los espíritus unidos en un gran sentimiento de consternación; las mujeres lloraban a los pies de las imágenes santas que alumbraban cirios y lámparas en alcobas abigarradas; los hombres impotentes se rebelaban contra el destino adverso como en las grandes catástrofes, reconociendo que ya habría librado la última partida y que todo estaban perdido; algunos crédulos no se daban por vencidos (Cáceres, 1921, p. 121).

El 18 de enero de 1881 — tal como nos sigue narrando Zoila Aurorase escuchó el sonido del redoble de tambores y el paso marcial del vencedor desfilando por las calles de Lima, mientras los negocios estaban 
cerrados; las casas, abandonadas; y un sinfín de banderas extranjeras flameaban en diversas casas para ser consideradas de propiedad foránea y evitar saqueos o incendios por parte de los chilenos.

Antes que el ejército enemigo llegara a la capital, una parte importante de los ciudadanos decidió irse de Lima. El resto de ciudadanos, sin capacidad de movilizarse, permaneció en sus casas:

Una sexta parte de la población, entonces de 100000 habitantes, había huido con numerosos días de anticipación a Chancay, Ancón, Huacho, a los buques de guerra y mercantes del Callao, habiéndose alejado algunas familias hasta Tarma y Jauja. En la ciudad, los conventos y hasta los templos habíanse convertido en campamento de refugiados (Dávalos y Lissón, 1947, p. 181).

Algunos pidieron asilo a embajadas extranjeras o instituciones religiosas, pues era improbable que el ejército rival las saqueara, como el caso de la poeta Lastenia Larriva:

Entre la mañana del 17 de enero y al atardecer de ese mismo día llegaron cientos de refugiados a conventos, colegios y consulados. Lastenia Larriva, quien años después recordaría el instante cuando recibió la noticia sobre el arribo de los chilenos a las puertas de su hogar, cuenta cómo ella y su familia buscaron asilo en el Colegio Belén. En este lugar, aparentemente resguardado por la bandera francesa, Larriva recibió dos noticias que la conmovieron profundamente: una de ellas fue el desastre de la patria y el otro la muerte de su esposo, quien junto a su hermano y su cuñado cayeron peleando en Miraflores. A partir de ese momento Larriva y su hermana lucieron las tocas de viudas (Mc Evoy, 2011, p. 346).

La situación de la ciudad durante las primeras semanas de ocupación era tensa, tal como testifica Antonia Moreno. El enemigo controlaba la capital y limitaba el acceso a todos los espacios públicos de Lima: «no era fácil, pues, circular en ese ambiente dominado por el enemigo» (Moreno de Cáceres, 1979, p. 16). Las calles y los mercados estaban vacíos.

Una de las primeras humillaciones en desmedro de la población peruana fue la celebración de misas fúnebres en honras a sus caídos en pleno corazón limeño:

El 27 de enero el capellán del ejército invasor, Florentino Fontecilla, solicitó permiso para celebrar honras fúnebres en la catedral de Lima, en memoria de los militares chilenos muertos en la acción de Miraflores, permiso que fue denegado por el canónigo Manuel Santiago Medina. No obstante ello, Baquedano se impuso y las ceremonias se realizaron el 3 de febrero (Rivera Serna, 1984, p. 20). 
Las mujeres fueron víctimas de incesante acoso por parte de los soldados chilenos. Frente al temor, decidieron disfrazarse de hombres, colocarse ropas anchas para disimular su aspecto físico e incluso encerrarse en casa la mayor parte del tiempo:

Las damas no asomaban a la calle; no se les veía en ninguna parte. A misa iban muy de madrugada, bien arrebozadas, en sus elegantes mantas chinas, cuyos tupidos encajes ocultaban parcialmente sus bellos rostros. Los chilenos decían: se nos había informado que las limeñas eran muy bonitas, pero ¿dónde están que no las vemos? (Moreno de Cáceres, 1979, p. 16).

Para colmo de males, las tropas chilenas se encargarían de saquear el inmobiliaria de la Universidad San Marcos y la Escuela de Bellas Artes y Oficios, donde se adiestraba al cuerpo profesional de nuestro país. Esto provocó la ira frustrante del poblador de a pie, pero no podía realizar alguna acción concreta para detener el saqueo, más que llorar o simplemente vociferar tímidamente su indignación.

Como el propósito era destruir y saquear, convirtieron en cuarteles el colegio de San Carlos, en donde funcionaba la célebre universidad de San Marcos, con las distintas facultades que la componen, y la nueva Escuela de Minas, la Escuela de Medicina, llamada antes colegio de San Fernando; la Escuela de Artes y Oficios, el Colegio Militar, todos establecimiento destinados al estudio de las ciencias y de las artes, los primeros en Sudamérica por sus espaciosos locales, ricas bibliotecas, preciosos surtidos de máquinas, instrumentos, aparatos y de cuantos elementos puedan necesitarse para la más alta instrucción en los diversos ramos del saber, y de un mobiliario magnífico (Paz Soldán, 1979, tomo III, p. 115).

Con el transcurso de las semanas, el Gobierno chileno designó a Patricio Lynch como gobernador interino de Lima y garantizó la neutralidad de los extranjeros en este conflicto, por ende, su integridad física y pertenencias serían respetadas. La «normalización» de la vida cotidiana generó que muchas personas regresaran a su actividad, como es el caso de Adriana de Verneuil, estudiante en un convento exclusivo para señoritas desde los inicios de la guerra, pero que en plena ocupación tuvo poca asistencia porque muchas familias huyeron de Lima o no tenían medios financieros para cubrir esos gastos:

Muy pocas niñas vinieron ese año al colegio no solo de provincias sino de la misma Lima sin quererse separar de los seres queridos, en el momento del peligro que todos presagiaban [...] solo tres alumnas éramos las de la segunda división ese año: Estefanía Gonzales, Ester Bielich y yo. Todo el clan chileno había desaparecido: las Irrarázabal y 
sus primas hermanas las Casanuevas, la Godoy y unas cuantas chicas más. Era un gran bien, pues resultaba muy difícil disimular ante ellas nuestras impresiones de a cada rato buenas o adversas, según las circunstancias (Verneuil de González Prada, 1947, p. 183).

Si realizamos un balance del primer año de ocupación, se recrearon distintas leyes para regular la vida de la capital, se transformó el sistema administrativo e incluso fue la oportunidad para que las tradiciones «burguesas» fueran cuestionadas y las costumbres populares sean practicadas sin restricciones o cuestionamientos. Por ejemplo, se implantaron «naturalmente» las peleas de gallos, prohibidas por la élite. Pero ello no fue motivo suficiente para frenar totalmente los permanentes intentos de robo a los que estaba sometida la población limeña, tal como testimonia Antonia Moreno:

Repuesta del susto, me dirigí a pedir alojamiento a alguna amiga, porque mi casa en San Idelfonso estaba en poder del jefe chileno que vivía al frente. Este soñó, sin duda, que la ocupación de Lima por sus tropas le daba derecho para adueñarse de las mansiones pertenecientes a los jefes peruanos $y$, a mano militar, se instaló en mi domicilio. Parece que mi salón de palo de rosa y damasco perla y carmesí atrajo sus simpatías; pues, sin más preámbulo, ordenó que lo trasladasen a su residencia. Su amor a los ajeno era decidido, pues en casa no queda nada (Moreno de Cáceres, 1979, p. 18).

En agosto de 1881 se conformó el Gobierno transitorio, llamado el Gobierno de la Magdalena, liderado por Francisco García Calderón. Ello representó un gran alivio para la población, porque aparentemente podían firmar un tratado de paz que cesara las hostilidades en contra de la población civil. Sin embargo, el objetivo de los chilenos era que los peruanos firmaran la cesión de territorio nacional. La negativa de la representación gubernativa nacional generó que muchos fueran conducidos a campos de prisioneros en la ciudad chilena de Rancagua, lo que provocó el pesar en la población peruana por la situación de sus compatriotas.

Pero el descabezamiento gubernativo no solo fue realizado en agosto de 1881. Patricio Lynch ofreció un plazo de 15 días a los limeños para entregar toda clase de armas que tuvieran en su poder. La pena que se aplicaría a los infractores consistía en una multa de 10 veces el valor del armamento incautado o la prisión, en caso de no efectuarse el pago:

Un buen número de limeños son sentenciados a la pena de apaleamiento por portar armas en el año de 1881. Así a Rocco, Delgado y Patricio Reyes se les encontró armas, siendo condenados al algo de una multa; los dos primeros pagaron, no así el tercero. Otro limeño 
de apellido Buitrón fue hallado con tres rifles y sables. Realizada la investigación se sancionó al administrador del predio, Álvarez Pinillos, a la pena de seis años de prisión o al pago de 1340 pesos (Reyes, 1984, p. 67).

Como hemos apreciado, las anécdotas y pormenores en torno a la vida cotidiana son múltiples al momento de describir el comportamiento de la población, su preocupación, su desazón por las derrotas y el acoso a los civiles, quienes sufrieron el horror de una guerra en toda su magnitud. Era una situación que los pobladores capitalinos sintieron y que hasta hoy provoca tristeza escuchar o leer.

Por tanto, estamos frente a una capital sometida militarmente a voluntad del rival y una población, que dos años antes estaba alentada por una rápida victoria, recordaba ello como un anhelado recuerdo que nunca sucedió. Ahora estaba sumida frente a la voluntad del enemigo.

\section{2}

Los primeros pasos para la firma de paz entre nuestro país y Chile tuvieron iniciativa de Estados Unidos. Una primera instancia fracasó en 1880, en la famosa conversación en la embarcación Lackawanna, pero ello no fue motivo para impedir el apoyo norteamericano.

Las intenciones de Estados Unidos eran apoderarse de Tarapacá y, para ello, convenía que el Perú aún mantuviera su posesión, aunque la falta de una fuerza bélica sólida en el Pacífico impidió someter a los chilenos. Pero lo que no realizó el poder bélico lo hizo la diplomacia. Hurlbut, el artífice de este paso, falleció en el proceso. El Gobierno transitorio nacional emitió una nota en la que expresó su sentir por un hombre «que tan notorios y reiterados testimonios nos ha dado de su amor al Perú y de su vida decisión de mantener a todo trance nuestra integridad territorial» ${ }^{3}$.

Los intentos por conservar intacto el territorio nacional no llegaron a buen puerto. Los peruanos de la época fueron testigos del desmembramiento de su nación, como si el destino no tuviera algún tipo de piedad.

\section{Conclusiones}

Construir la vida cotidiana de un país es un reto, como habíamos señalado en las líneas introductorias, porque requiere, además de un meticuloso trabajo de análisis de fuentes, el combinar los puntos de vista en torno a un hecho histórico. Si bien el discurso fue homogéneo, porque han intervenido en gran parte de este trabajo testimonios de peruanos,

3 Carta N 90 al comisionado especial del Supremo Gobierno en el sur (28 de marzo de 1882) (Puente Candamo y Puente Brunke, 2016, p. 205). 
ello no debe mermar que relataban con mucha objetividad sobre cómo la sociedad peruana fue cambiando a partir de un hecho que movilizó todo el sector político, económico y social de nuestro país.

Los libros-memoria se convirtieron en una herramienta fundamental, en este caso para narrar aspectos que muchas veces son eclipsados, pero que escenificaron a ese país trasformado por un aspecto bélico, con secuelas que hasta hoy permanecen en la memoria de los peruanos.

Es importante agregar que estos testimonios son realizados exclusivamente por los sectores letrados del país. Las clases populares, cuya voz no se incluye en este trabajo, aún deben ser ahondadas y así conocer el grado de concientización por el que participaron.

\section{Contribución del autor}

Emilio Rosario ha participado en la concepción del artículo, la recolección de datos, su redacción y aprobación de la versión final.

\section{Fuente de financiamiento}

Autofinanciado.

\section{Conflictos de interés}

El autor declara no tener conflictos de interés. 


\section{REFERENCIAS BIBLIOGRÁFICAS}

Alayza y Paz Soldán, L. (1947). Historia y romance del viejo Miraflores. Lima: s.e.

Cáceres, Z. A. (1921). La campaña de la Breña. Lima: Americana.

Caivano, T. (1969). Historia de la guerra de América entre Chile, Perú y Bolivia. Lima: Museo Naval.

Certeau, M. de (1996). La invención de lo cotidiano. 1 Artes de hacer. Ciudad de México: Universidad Iberoamericana.

Dávalos y Lissón, P. (1947). ¿Por qué hice fortuna? Relato inspirado en el recuerdo de una vida dedicada a conseguir la independencia y la tranquilidad de espíritu que da la posesión del dinero adquirido y guardado no con avaricia. Años de 1883 y 1885. Lima: Imprenta y librería Gil.

Fuentes, M. A. (1881). Ramillete o repertorio de los más piramidales documentos oficiales del gobierno dictatorial. Lima: Universo.

Markham, C. (s.f.). La guerra entre Perú y Chile. Lima. Esmar.

Mayer, D. (1981). Memorias. Lima: Seminario de Historia Rural Andina.

Mc Evoy, C. (2011). Guerreros civilizadores. Política, sociedad y cultura en Chile durante la Guerra del Pacífico. Santiago de Chile. Centro de Estudios Bicentenario.

Moreno de Cáceres, A. (1979). Recuerdos de la campaña de la Breña. Lima: Milla Batres.

Mücke, U. y Velázquez, M. (Eds.) (2015). Autobiografía del Perú republicano. Lima: Biblioteca Nacional del Perú.

Paz Soldán, M. F. (1979). Narración histórica de la guerra de Chile contra el Perú y Bolivia. Tomos I, II y III. Lima: Milla Batres.

Puente Candamo, J. A. de la y Puente Brunke, J. de la (Eds.) (2016). El Estado en la sombra. El Perú durante la ocupación chilena. Documentos administrativos (diciembre de 1881-julio de 1882). Lima: Fondo Editorial de la Pontificia Universidad Católica del Perú.

Rivera Serna, R. (1984). La ocupación chilena de Lima: aspectos políticoadministrativos. En A. Reyes, W. Kapsoli y otros (1984), La Guerra del Pacífico. Tomo I. Lima: Fondo Editorial de la Universidad Nacional Mayor de San Marcos.

Rosario, E. (2013). Parlamentos en conflicto. La Guerra del Pacífico y el Congreso de la República (1879-1881). Lima. Fondo Editorial de la Universidad Nacional Mayor de San Marcos y Seminario de Historia Rural Andina.

Verneuil de González Prada, A. (1947). Mi Manuel. Lima. Editorial Antártica. 
Wu Brading, C. (1986). Testimonios británicos d la ocupación chilena de Lima. Lima: Milla Batres.

Zanutelli, M. (1981). Semblanza antológica de la época. La gesta de Lima. Lima. Imprenta del Ministerio de Guerra.

Recepción: 14/4/2018 Aceptación: 31/8/2018 